Pakistan Journal of Social Sciences 9 (2): 79-88, 2012

ISSN: $1683-8831$

(C) Medwell Journals, 2012

\title{
Spatio-Temporal Analysis of Roads Connectivity and Accessibility Pattern: A Case Study of Northeastern Nigeria
}

\author{
${ }^{1}$ Abbas Bashir, ${ }^{2}$ Sadiq Abdullahi Yelwa and ${ }^{3}$ Labaran Mariya \\ ${ }^{1}$ Department of Geography, Taraba State University, Jalingo, Nigeria \\ ${ }^{2}$ Department of Geography, Usmanu Danfodiyo University, P.M.B. 2346, Sokoto, Nigeria \\ ${ }^{3}$ Department of Geography, Nasarawa State University, Keffi, Nigeria
}

\begin{abstract}
The study tries to compare the pattern of road connectivity and nodal accessibility development in a portion of Northeastern Nigeria (made up of areas in Former Borno and Gongola States) between 1955 and 2010. Data for the study was derived from the road map of Nigeria 1955 and 2010 as well as the 2006 National population census figures. Techniques in network analysis and the Man-Witney U test were used in analysing the data. The study reveals that the 1955 pattern of road network development in the region was very typical of the early stages of network development as propounded by Taaffe with isolated sub-graphs, very sparse connectivity and very low accessibility. The study further reveals that the post-independence developments in the country however, lead to significant improvements in both total connectivity and nodal accessibility in the North-East sub-region even though the overall pattern achieved by the year 2010 is still far from satisfactory.
\end{abstract}

Key words: Transport, regional, accessibility, connectivity, interaction, development, GIS

\section{INTRODUCTION}

Transport, some people argue is the Sine-quanon for economic development especially for the developing countries of Africa. According to Hoyle (1973) this view was aptly held by Lord Lugard that the material development of Africa may be summed up in the one word transport. The concern for transportation in Nigeria as in other developing countries is in its application to promote rapid economic development and to enhance political stability. In this context therefore, transport plays a formative role as a power for economic growth and socio-political advancement, etc. In other words for any meaningful economic and political progress to be achieved in any part of Nigeria, the provision of some measure of transport is essential. This probably accounts for the Stanford Research Institute's Report on the Economic Cooperation for Transport Development of Nigeria in 1981 which lead to significant improvement in transportation as a means for opening up the vast areas of the country for economic development (UNDP, 2001). Since, the country's attainment of political independence in 1960, the various development plans of Nigeria have accorded high priority to the development of transport infrastructure. This includes investment in providing airports, seaports, roads and bridges, etc. In addition, the various state governments also provide funds for the construction and maintenance of roads in particular (which is the most important means of movement) in order to enhance the degree of accessibility of our major and small towns and villages for improve interaction.

Roads network development in Nigeria is generally a phenomenon of the 20th century since the introduction of railway transportation in 1898 . Since, 1925 when there were only a few kilometers of roads that linked some provincial administrative centers the network has developed to an advanced state consisting of thousands of kilometers of asphalt-surfaced roads that remarkably changed the pattern and degree of connectivity and accessibility in the country. For example, the total roads network increased from $96,375 \mathrm{~km}$ in 1972 to $>132,771 \mathrm{~km}$ in 1982 representing a growth of $38 \%$. Similarly, the total length of asphalt surfaced roads in Gongola State increased from about $357 \mathrm{~km}$ in 1976 to about $600 \mathrm{~km}$ in 1980 , representing a growth of $68 \%$ (Bashir, 1982). These figures have since almost doubled following the activities of Federal, States and Local Governments including those of specialized agencies like the River Basin Development Authorities, DFRRI, etc. The result was the emergence of a system of roads netting the entire national landscape, changing the accessibility and connectivity pattern for the settlements. Enhanced accessibility within a country creates conditions that favor greater interaction between people and places. The intensity of this interaction which

Corresponding Author: Abbas Bashir, Department of Geography, Taraba State University, Jalingo, Nigeria 
may be manifested in the movement of goods and people between places, becomes a measure not only of national integration but also the level of development within the country.

It is assumed that the pattern of provision of roads (i.e., connectivity and accessibility) is a reflection of the pattern of economic development. Therefore, a change in the pattern of accessibility means a change in the incidence of economic growth (Gauthier, 1973). As a developing country where transport network expansion is almost necessary for improvement in the economic performance of sectors and regions, a strong positive relationship may therefore be expected between the pattern of roads network expansion and economic development in Nigeria. The North East part of Nigeria (comprising Adamawa, Borno, Bauchi, Gombe, Taraba and Yobe States) is one of the geographical segments of the country that suffered the problems of backwardness in economic and more especially road network development even though Nwafor (1982a) of the view that one of the achievements of Nigeria since the mid 1960's has been in the development and rapid expansion of road connections.

This study tries to examine connectivity pattern in the Northeastern region of Nigeria between 1955 and 2010. Since, as noted earlier road development is not an independent variable of change, researchers shall try to adduce reasons for the change and speculate on how the pattern of roads network development is related to spatial interaction and economic progress in the region and propose further imperatives necessary to stimulate economic development in the rural areas of the region.

Transport network development (The theoretical background): At the early stages of economic growth transport, provision or expansion obeys the economic theory of demand and supply in which the role of transport is essentially permissive in the process of economic development. As the economy progresses the role of transportation becomes more complementary in nature until the economy is well advanced and the transport system becomes very complex and efficient. In other words, transport networks are subject to change at any time and they display characteristic sequences of development even though this may be less obvious. These sequences have been formalized into a number of evolutionary models which provide insight into the nature of network change (Taaffe et al., 1996).

Demand for movement within an area is generated by two sets or categories of forces, i.e., internal and external forces. These forces acting together and severally are key factors in the dynamics of transport network development. Models of network change have identified a number of stages of network development as exemplified by Taaffe et al. (1963). Firstly, this model assumes that the area served by a network is a self-contained unit which does not interact with places beyond its boundaries. Secondly, it also assumes that the network evolved around a fixed distribution of nodes. However, the implication is that routes develop exclusively in response to demand for movement created by existing nodes (i.e., due to internal forces). Finally, routes are assumed to be straight-lines connecting nodes on an isotropic surface but they may be differentiated in terms of their quality and capacity which are related to the class of nodes which they connect.

The Taaffe et al. (1963)'s initial descriptive model of transport network development is an inductive one based on data largely concerning Nigeria and Ghana although, they also examined the network expansion process in Brazil, Kenya and Malaysia, all of which show similarities in the way route network development proceeded. This model started with a stage in which there are series of scattered ports of equal size along a segment of coastline. Small trails extend from these small ports to their limited hinterlands so that in this phase there is no complete regional network but a number of independent networks. At a second stage, some of the ports disappear in the face of unmatched competition. From these large ports (which owe their growth to such factors as favorable location at the mouth of navigable rivers or with respect to access routes to the interior and to the aggressive entrepreneurship present in some ports but absent in others), penetration lines reach the interior mineral or agricultural resource areas. These initial penetration lines may be roads, canals or railroads so that at this stage there are at least two trees (lines of transport) with small number of links per tree.

The second stage is probably most crucial because it establishes the fundamental alignments of the future network pattern (connectivity) in the region. In the colonial countries of Africa and Asia the early inland penetration of routes has been attributed to three important reasons. The colonial authorities in the African countries built railroads to the interior as an aid to general economic development and in the interest of political administration (Nwafor, 1982b). The second reason accounting for the interior penetration arises from the notion of complementarity. Many of the underdeveloped nations contained mineral resources that were in high demand abroad. Access had to be created to the resource areas linking them with the ports and therefore the outside world. It was in this way that railroads were built from Port-Harcourt to the Enugu coal mines and later to the Jos 
Tin mines in Nigeria and finally into the Northeast through the rail stations at Bauchi, Gombe and Maiduguri. Similarly, it was by linking the cash crop producing areas with railroads to the ports that this was also achieved. For example, the railway link between Lagos and Kano was essentially to facilitate movement of cotton, oil nuts, etc. for export and hide/skin, groundnuts and cotton from the North-East.

In the third stage of network, development is the development of feeder routes. This can be seen as a diffusion process in which the density of the road network decreases with distance from the major centers of economic activity. This is still very much evident in the road network pattern in Nigeria (a dense network in the Southern part of the country compared to the very low connectivity in the Northern part).

During the fourth and fifth stages new centers and new transport links emerged and grow with diagonal links. At the final stage, the network becomes very complex as high priority linkages also develop. At this stage, some centers which have greater initial advantage (in location and linkage) will tend to acquire dominance over a large hinterland at the expense of other centers. The demand for transport between the larger centers will be very high. Consequently, this situation leads to the emergence of high priority main roads as in the case of trunk A roads and recently, the express roads in Nigeria.

The sequence of network development in reality may not necessarily follow the stages described earlier, even though the model serves as useful guide in understanding roads network development. However, it is possible to make a spatio-temporal comparative analysis of network change using some quantitative models similar to the ones developed by Kansky (1963).

Transport Network Analysis Models: In studying networks geographers ask and try to answer a wide range of questions. They are interested in the number of nodes and edges in a network and whether the network is material or abstract what the network carries, e.g., vehicles, materials or information and the volume of traffic it actually carried. Geographers are also interest in the pattern of lines, distances covered and the efficiency of the network or how well it serves all parts of the country, region or area.

To answer these questions two categories of network description are sometimes used. These are the morphological and functional approaches. The functional approach is based on the dominant use to which a network is put. This is different from and indeed not appropriate for the study of either structural pattern or degree of connectivity of a network. The morphological approach on the other hand focuses on the accessibility and orientation characteristics of a network.

Morphological description of networks involves principally a uniform surface distinction analysis. This assumes that the movement of goods and people in an area is equally easy and cheap at all points over all distances and in all directions. This infers apriori that:

- There is an infinite number of routes

- Geodetic distance will alone determine the time, effort and cost of movement between any two points

- All locations can be reached directly from all other locations, i.e., there is total connectivity

- Movement can be initiated at any point within the area i.e., total accessibility

- The surface is undifferentiated over all geographic scales

The approach therefore relies on the understanding that distortions in the uniform surface may result due to physical features and then by the process of human settlement.

The measures of distortions which Hay (1973) recognised are road density, route factor and access point. Road density which is defined as length of road per unit area has its limitations, most important of which is the fact that it does not have any relationship with the intuitive concept of accessibility. This criticism is also true of the route factor index that is the ratio of the geodetic distance to the route distance. These measures simply allow classification of whole networks, nodes and individual links based on morphology.

The morphological and functional approaches do not provide adequate comparative measures of network characteristics which are intuitively and practically acknowledged to be important (Hay, 1973). An alternative approach is the topological method which is based on graph theory and matrix Algebra, pioneered by Garrison, Marble and their associates. Graph Theory is a branch of Mathematics that investigates the properties of simple topological diagrams, known as graphs which can be drawn to represent many geographic networks. The graphs identify the terminals and junctions of the network and the links between them. This theory is more concerned with the numbers of vertices, the numbers of edges connecting these vertices, the number of complete circuits formed and the number of graphs formed in a network rather than with distances in kilometers between them or the traffic flow along them.

Graph Theory is used by geographers to measure hierarchical order, branching ratio, connectivity, shortest 
path, network shape, density, pattern, orientation and spacing. Even though, Bela devised modern techniques on Graph Theory, the idea behind the graphical techniques of network analysis is to provide a numerical value that can be used to describe a network quantitatively and to compare exactly one network with another. Important network characteristics which Graph Theory tries to describe quantitatively are the degree of connectivity and accessibility as defined below:

Connectivity index: In a system of planar graph such as represented by roads network where the intersection of two edges is always a vertex, two nodes or vertices are said to be connected if there is a link (e.g., road) linking them. Connectivity of a network is therefore simply defined as the degree of connection between all the nodes in a system and the connectivity index is a measure of the relative simplicity or complexity of the network.

There are a number of graph-theoretical measures used in evaluating the connectivity of nodes. These include the Beta index, the Gamma index the cyclomatic number and the Alpha index. What is common to all these measures is that they are based on the relationship between the number of edges and vertices in a network.

The Beta index $(\boldsymbol{\beta})$ : For any given number of places, the more routes there are the greater the choice of routes one has from place to place and therefore the greater the connectivity of the network. The $\beta$-index describes the number of edges present in relation to the number of vertices (v) to be connected. This is given by the equation:

$$
\beta=2 \mathrm{a} / \mathrm{v}
$$

It is therefore the simplest measure of connectivity. In this case the higher the index (ranging between 0.5-3), the greater the connectivity.

Gamma-index: The Gamma index $(\gamma)$ is the ratio between the actual and the maximum possible number of edges in a graph, given by the equation:

$$
\gamma=\frac{\mathrm{e}}{3(\mathrm{v}-2)}
$$

Its value ranges between $0-1.0$, i.e, $0 \leq \gamma \leq 1.0$. And that the connectivity increases as $\gamma$ tends to 1.0 . This is some times expressed as a percentage, i.e.:

$$
\gamma=\frac{\mathrm{e}}{3(\mathrm{v}-2)} \times 100
$$

Cyclomatic number: This index tries to identify or count the number of loops, trees or sub-graphs. This is based on the understanding that well connected networks are those that contain a number of loops. The cyclomatic number $(\mu)$ is given by:

$$
\mu=\mathrm{e}-\mathrm{v}+\mathrm{g}
$$

where, $\mathrm{g}$ is sub-graph ranges from 0 to $(2 \mathrm{v}-5)$.

Alpha index $(\alpha)$ : The $\alpha$-index derives from the cyclomatic number. It is a ratio based on number of circuits in a network, a circuit being a path through a network which begins and ends at the same node, without passing over any edge more than once. It is computed using the equation:

$$
\alpha=\mathrm{e}^{-\mathrm{v}}+\mathrm{g}
$$

Or:

$$
\alpha=\frac{\mu}{2 \mathrm{v}-5} \times 100
$$

where, $g$ is sub-graph. The $\alpha$-index therefore measures the ratio between the actual number of loops in a graph and the maximum possible number.

The $\beta, \alpha$ and $\gamma$ indices are among several others developed by Kansky (1963) and have been widely used. One of the problems with these measures of connectivity is their high level of abstraction, ignoring the geographical magnitude of the networks by simply assigning $s$ value of 1 , to each edge and vertex.

The efficiency of the $\alpha, \beta, \gamma$ and $\mu$ indices in terms of their ability to discriminate between six alternative networks of approximately the same sequence were all tested (Werner, 1968; Hay, 1973; Loure and Moryadas, 1975) but none was able to discriminate between alternative configurations such as square or circular networks. Werner also found the Beta and Gamma indices to be theoretically redundant.

In particular, the $\beta$ and $\alpha$ indices do not provide good measures in about $50 \%$ cases for either spatial or temporal comparison between network forms. Werner consequently recommends the use of the Alpha index in preference to either the Beta or Gamma index in order to evaluate and compare network connectivity.

Accessibility index: Accessibility is understood here to mean the reachability of a vertex in a system of roads network. This is evaluated by means of the accessibility Index A which is calculated as: 


$$
A_{i}=\sum_{i=1, j=1}^{n} d_{i j}
$$

where, $d_{i j}$ is distance (i.e., number of links) between the ith and the jth place. Other measures of accessibility are the Koning index $\mathrm{k}=$ Max. $\mathrm{d}_{\mathrm{ij}}$, i.e., the maximum of the distances from the $\mathrm{jth}$ vertex to each of the other vertices in the network. In this regard also, distance is the number of intervening edges between two vertices, measured along the shortest path, regardless of the actual mileage involved. The vertices with the highest associated number (i.e., ki value) are the least connected and therefore most peripheral of the locations in the graph (i.e., low accessibility). In both cases the computation is based on connectivity matrices. The accessibility index is however most commonly used because it enables better discrimination between modal accessibility in similar networks much more than the Koning Index.

The study area: The Northeastern region of Nigeria is the area which was created in 1967 and bounded between longitudes $8^{\circ} 35^{\prime}-14^{\circ} 40^{\prime} \mathrm{E}$ and latitudes $6^{\circ} 15^{\prime}-13^{\circ} 45^{\prime} \mathrm{N}$. The region now comprises the states of Adamawa, Bauchi, Borno, Gombe, Taraba and Yobe. Until 1976 these states shared a common history of development. However, after 1976 and particularly from 1991 each of these states pursued different policy initiatives in its development effort, each emphasizing the peculiar social, economic and spatial characteristic of its area. According to Akintola (1982), this study area consists of undulating plains and rising hills as well as the monotonous Chad basin plains characterize the topography of the Northeastern region. The region is generally well drained by a network of small and major rivers notable of which is the River Benue which has its headwater coming from the Cameroon highlands and flows Southwest wards. The HadejaJamare-Yobe river system drains into the Lake Chad from the highlands of North Central Nigeria while the Gongola river which rises from the Jos Plateau, flows through Bauchi and Gombe States into the river Benue in Adamawa State (Fig. 1). These rivers provide limited opportunity for river transport during the rainy season. The physical structure of the Northeast region constitutes both opportunity and constraints for the socio-economic development of the region. As an opportunity the physical features of this region represent an embodiment of resources which can be harnessed for its development. As constraint, the large mountain ranges, the floodable Chad plains and the major rivers had earlier constituted major limitation to intra-regional movement (interaction) of both people and resources by making roads construction very difficult or almost impossible. The nature of the terrain in the extreme East and South West of the region consists of flood plains, loaese plains, the high rise mountains and the extensive Benue flood plains had

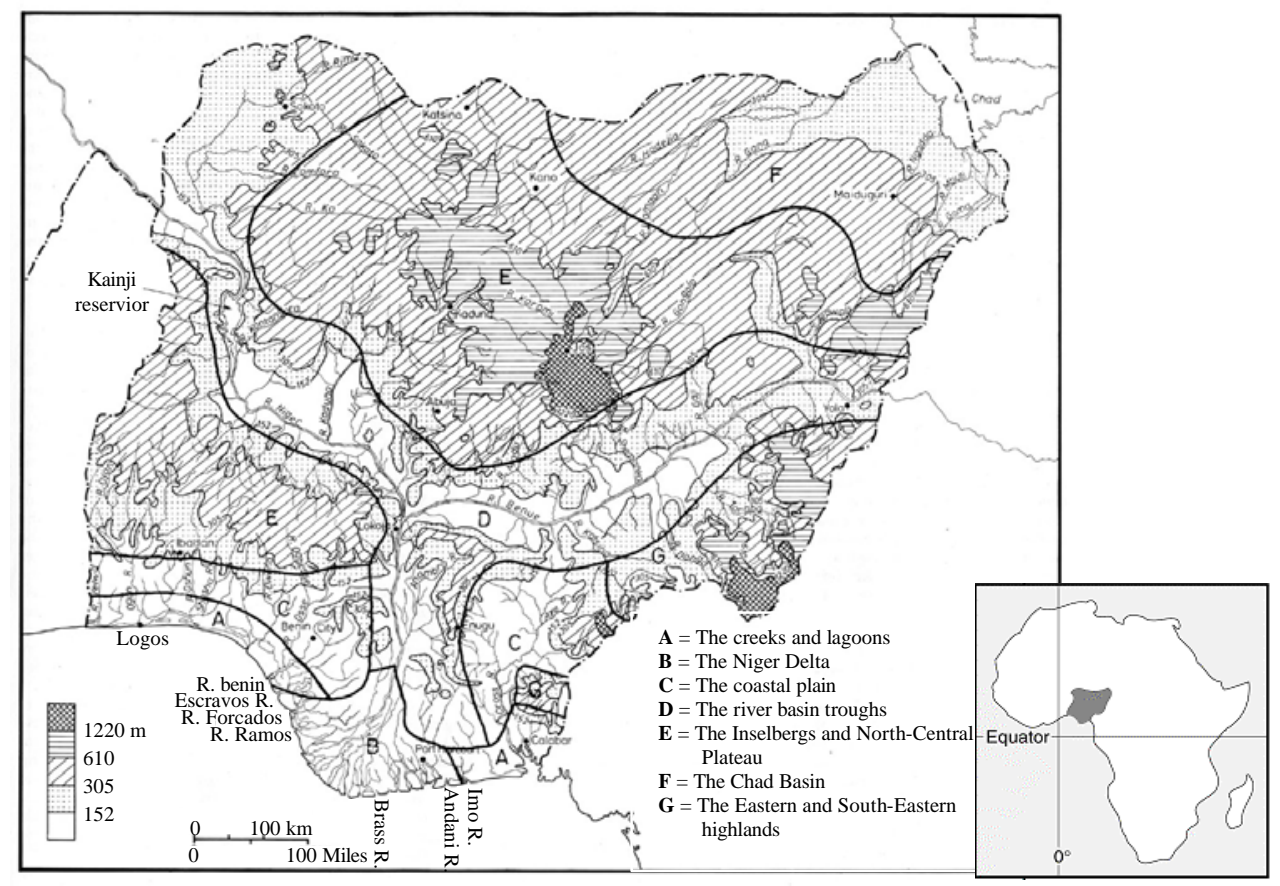

Fig. 1: The relief and river catchments across Nigeria (Akintola, 1982) 
probably been responsible to a reasonable extent, for the poor development of roads network in the areas in the early 1950 s.

Objectives: The general objective of this study is to assess the degree of structural change in road (transport) network pattern in parts of the northeastern region of Nigeria over a period of about 25 years (i.e., 1955-2010). Secondly, the study also tries to establish the relationship of transport network expansion (or change) with the change in interaction potential within the region. Specifically therefore the objectives are:

- To compare the degree of connectivity in the areas comprising since, around 1955 (colonial) and the 2010 (contemporary) patterns

- To compare the nodal accessibility in the area over the period 1955-2010

- To correlate accessibility with the interaction potentials of the various nodes within the area over the same period of change

Hypotheses: In trying to achieve the above objectives and following Kansky (1963), researchers hypothesis that:

- All networks undergo structural change and become more complex through time so that the Network $\mathrm{N}_{0}$ which is prior to $N_{t}$ in time $t$ is a simpler structure

- Simultaneously with the increasing complexity of networks is the enlargement of nodes (i.e., increasing interaction potential), in terms of more people and more economic activity, resulting in more movement, etc. Thus, researchers hypothesis that there is a functional relationship between network structures and regional characteristics

\section{MATERIALS AND METHODS}

For a comparative analysis of road network development over space and time two or more network maps of two or more periods must be studied. In this study, the 1955 roads map of Nigeria is used as the base map and compared with the 1980 roads network map of the North Eastern part of the country.

The analytical tools adopted are the measures of connectivity (the $\alpha$-index) which is probably more reliable (Hay, 1973) and the dispersion or Shimble index which itself is a derivative of the accessibility index. Although, accessibility modelling has been proposed now a days as a solution to these problems which uses GIS to calculate door to door travel times by public transport to a grid of points around the point of interest, resulting in a set of isochrones (journey time contours) within which the number of workplaces, households or residents can be calculated using census data (Weiping and Chi, 2010). These measures are based on the principles of graph theory (the topological approach). The accessibility indices of the various nodes are then correlated with the 2010 projected population figures of a sample of the nodes as surrogate for interaction potential using the spearman's rank correlation analysis. A Man-Whitney U test is also employed to test the significance of the change in accessibility of the nodes over the 25 years period.

In any region, there is a finite number of settlements (nodes) all over the landscape and in most countries of the world (Nigeria inclusive) roads are of various categories, differentiated either by capacity, quality, administration, etc. In the Northeastern region, settlements are so numerous that to achieve parsimony, especially in relation to space and time for this study, a purposeful sampling method is necessary for selecting nodes which are incorporated into the analysis. In this regard, all the pre 1989 local governments headquarters and other settlements which have a population of about 8,000 (2010 projected) constitute the sampling frame. On the other hand only the Trunk A and B roads, generally classified as better or motor-able go into the network analysis based on Akinola and Adalemo (1978)'s road classification.

\section{RESULTS AND DISCUSSION}

The explanation of topological structures using the principles of Graph Theory such as represented by roads network is concerned mainly with abstract configurations consisting of points and edges. The effort in this study is to analyze and compare the connectivity and accessibility of the nodes or settlements in a section of Northeast Nigeria. Specifically the road networks of 1955 and 2010 are compared to show the nature or extent of change in the roads network in the region $>45$ years period.

Connectivity: In this study, connectivity is defined as an expression of the degree to which a network permits direct movement between its various vertices or nodes. It is therefore a single aggregate measure relating to the structure as a whole. The measure of connectivity employed in this study is the Alpha $(\alpha)$ index, in preference to beta or Gamma index.

A sample of 45 nodes were selected and considered for both the 1955 and 2010 topological structures of the study area. However, for the 1955 structure only twenty nine of these nodes were how inter-connected by the Trunk A and B roads, unlike the 2010 structure where all (the same) forty five nodes had some connectivity. 
A comparative analysis of the 1955 and 2010 structures shows that by 1955 only $64.4 \%$ of the 45 selected settlements were served by one category of road or the other. This is further confirmed by a binary connectivity matrix analysis. A graphical analysis of the 1955 topological structure of roads and nodes however, reveals an Alpha $(\alpha)$ index of only 0.196 . This means only about $19.6 \%$ connectivity was achieved. The existence of a small sub-graph (Southern Taraba) is itself an indication of the degree of sparseness in the road links. This is much unlike the 1980 topological structure where all 45 nodes were somehow served by at least one artery. This is an improvement over the 1955 pattern. In 2010 an $\alpha$ connectivity index of 0.341 shows that road network development in the relatively better than the 1955 situation but cannot in any way be described as good even though it may have improved the degree of nodal accessibility of at least some of the settlements. While increased connectivity is naturally expected as development progress overtime, its impact on accessibility needs to be determined (Table 1 ).

Accessibility: Accessibility which is defined here as the ease of reach one node from another is a measure that is specific to individual nodes which are differentiated in terms of their location relative to one another. The measure of accessibility employed to describe how to reach each of the 45 nodes in the network is the accessibility index derived from graph theory and the Shimble-index that examines the degree of compactness or sparseness of a network. A standard deviation measure is also employed to further compare the 1955 and 2010 structures of accessibility.

Table 1: List of sample nodes

\begin{tabular}{llcl}
\hline Nodes & Name & Nodes & Name \\
\hline 01 & Gubio & 024 & Jalingo \\
02 & Bama & 025 & Sabongida \\
03 & Auno & 026 & Mayo Belwa \\
04 & Biu & 027 & Mickika \\
05 & Damaturtu & 028 & Mubi \\
06 & Damboa & 029 & Takum \\
07 & Fika & 030 & Wukari \\
08 & Gashua & 031 & Yola \\
09 & Geidam & 032 & Numan \\
010 & Gwoza & 033 & Garye \\
011 & Kukawa & 034 & Lau \\
012 & Maiduguri & 035 & Dakka \\
013 & Mongonu & 036 & Buni \\
014 & Ngala & 037 & Dapchi \\
015 & Nguru & 038 & Dikwa \\
016 & Potiskum & 039 & Gajigana \\
017 & Damasak & 040 & Mutumbiu \\
018 & Bali & 041 & Garba Chede \\
019 & Belel & 042 & Arege \\
020 & Gembu & 043 & Baga \\
021 & Gombi & 044 & Karamti \\
022 & Ibbi & 045 & Song \\
023 & Jada & - & - \\
\hline
\end{tabular}

The shortest path analysis which was based on Fig. 2 and 3 show the accessibility of the individual nodes relative to the network as a whole. The 1955 roads network pattern shows Maiduguri (Node 12) and Damaturu (Node 5) all in the Borno area had the best accessibility in terms of the binary connectivity matrix while most other nodes were either completely inaccessible or only partially accessible. This situation is very typical of the early stages of road network development as revealed in the Taaffe Model. However if the shortest part matrix of the 1955 topological structure of the roads is considered, Node 21 (Gombi) in Adamawa and Node 4 (Biu) in Borno were the best accessible with shortest path (accessibility) indices of 107 and 109, respectively. In this respect Maiduguri on the contrary and Damaturu dropped to rank 11th and 5th, respectively. The most inaccessible in 1955 among the connected nodes were Nodes 22, 29 and 30 (i.e., Ibi, Takum and Wukari) which together form an isolated sub graph. Within the main graph, Nodes 14, 18 and 40 (with shortest path index of 195, 214 and 213, respectively) were the least accessible.

Comparing the 1955 structure with the 2010 topological pattern of the roads network, Maiduguri and Damboa (Nodes 12 and 6) were the best-connected in terms of the binary connectivity matrix. However, considering the entire network (graph) Nodes 4, 6 and 32 (i.e., Biu, Damboa and Numan) are the most easily reachable. These nodes achieved associated number of 8,9 and 9 , respectively with shortest path distances of 173,173 and 183 links, respectively. Maiduguri in this respect ranked 4th with a shortest path distance of 187 links and an associated number of 9 .

The measure of the shortest path index seems to be better than the binary connectivity matrix method because the former considers the totality of the nodes and links in a network rather than only links joining nearest neighbor nodes in the binary connectivity matrix.

The Shimble index which is derived from the shortest path accessibility matrix provides a good index for comparing total networks. For example in the 1955 structure the Shimble index achieved was only 3,821 which shows that the network is less dense than the 1980 structure which had a Shimble index of 11,276 where about $64.4 \%$ of the nodes fall within a plus or minus one (61SD) standard deviation of the mean shortest path index (The calculated mean is 250.57 links and the standard deviation is 50.5). Compared to the 1955 structure and if all the 45 nodes are taken into account, the mean shortest path index for 2010 network is 84.91 with a standard deviation of 79.27 . This shows that only 16 nodes or $36.6 \%$ (16 nodes) fall within plus or minus one standard 
Pak.J. Soc. Sci., 9 (2): 79-88, 2012

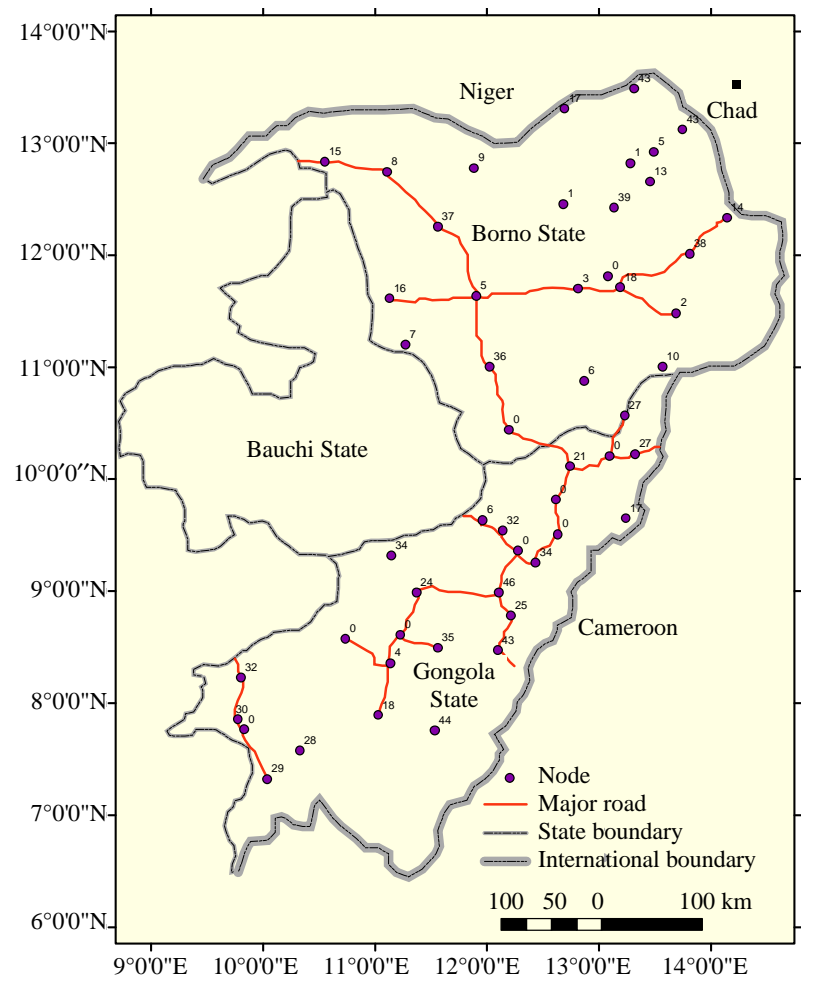

Fig. 2: Roads network as at 1955

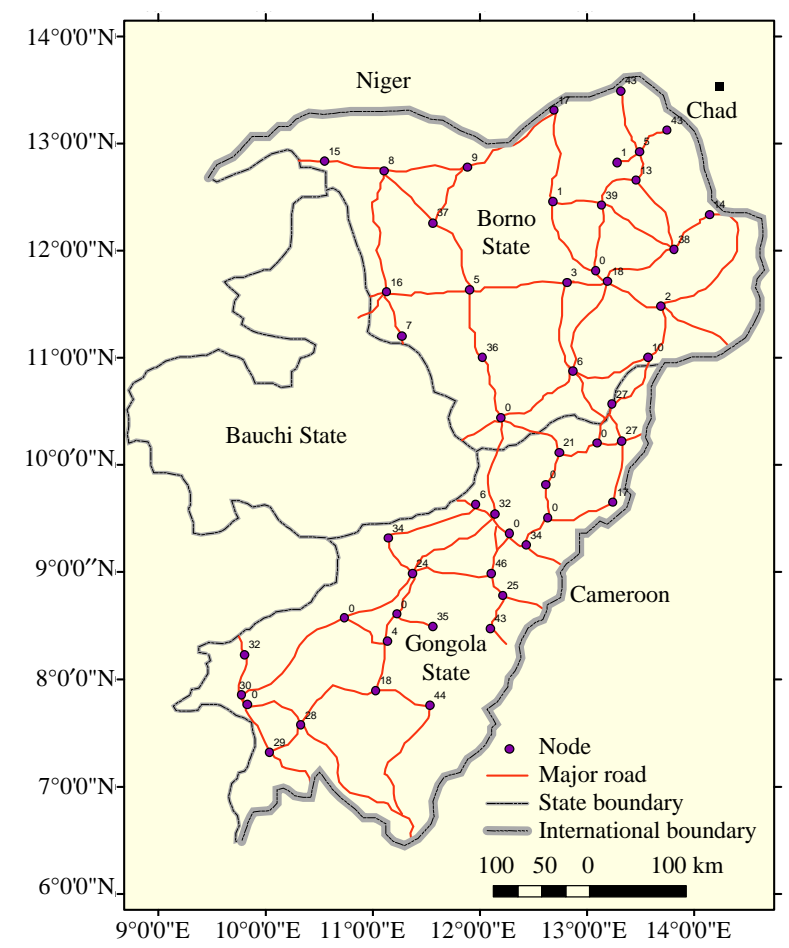

Fig. 3: Roads network as at 2010 
deviation $( \pm 1 \mathrm{SD})$ of the mean shortest path index. Thus, the 2010 roads network represents significant positive change over the 1955 pattern. This is confirmed by a Mann-Whitney U-test of significance (Table 2).

The null assumption here is that the difference in the 1955 and 2010 patterns of nodal accessibility observed in the region is not significant so that there is no difference between the two patterns. In other words, any difference observed in the two patterns is due entirely to chance in the selection of nodes. The Mann-Whitney U-test which is non-parametric is calculated using the equation:

$$
\begin{aligned}
& \mathrm{U}=\mathrm{n}_{\mathrm{x}} \mathrm{n}_{\mathrm{y}}+\frac{\mathrm{n}_{\mathrm{x}}\left(\mathrm{n}_{\mathrm{x}}+1\right)}{2}-\mathrm{r}_{\mathrm{x}} \\
& \mathrm{U}=\mathrm{n}_{\mathrm{x}} \mathrm{n}_{\mathrm{y}}+\frac{\mathrm{n}_{\mathrm{y}}\left(\mathrm{n}_{\mathrm{y}}+1\right)}{2}-\mathrm{r}_{\mathrm{y}}
\end{aligned}
$$

From Table 2, a Mann-Whitney U-value of 209 (the least) was calculated. Compared to the critical U-value of 504 at the 0.05 level of significance which is greater than the calculated value, the earlier assumption of no difference in the two (i.e., 1955 and 1980) patterns of accessibility is rejected. This means that the first assumption that the network $\mathrm{N}_{0}$ which is prior to $\mathrm{N}_{\mathrm{t}}$ in time $\mathrm{t}$ is a simpler structure is to some extent confirmed. This is further supported by the Shimble index of 3821 (in 1955) compared to the more complex 1980 network with a

\begin{tabular}{|c|c|c|c|c|c|}
\hline $\begin{array}{l}1986 \text { Index of } \\
\text { Accessibility }\end{array}$ & $\begin{array}{c}\text { Nodal } \\
\text { rank }\end{array}$ & $\begin{array}{c}2010 \text { Index } \\
\text { of Nodal } \\
\text { Accessibility }\end{array}$ & $\begin{array}{c}\text { Nodal } \\
\text { rank }\end{array}$ & $\begin{array}{l}\quad 2010 \\
\text { Accessibility } \\
\text { Index (Cont'd) }\end{array}$ & $\begin{array}{c}\text { Nodal } \\
\text { rank }\end{array}$ \\
\hline 170 & 56.0 & 215 & 37.5 & 356 & 5.0 \\
\hline 131 & 67.0 & 241 & 28.5 & 277 & 15.0 \\
\hline 109 & 73.0 & 189 & 50.0 & 243 & 25.0 \\
\hline 116 & 70.0 & 173 & 54.5 & 183 & 52.0 \\
\hline 167 & 58.5 & 197 & 46.0 & 308 & 12.0 \\
\hline 149 & 64.0 & 173 & 54.5 & 228 & 31.5 \\
\hline 195 & 47.0 & 250 & 23.0 & 290 & 14.0 \\
\hline 180 & 53.0 & 253 & 22.0 & 198 & 45.0 \\
\hline 141 & 65.0 & 260 & 20.0 & 221 & 34.5 \\
\hline 214 & 39.0 & 207 & 42.0 & 220 & 36.0 \\
\hline 107 & 74.0 & 320 & 8.0 & 215 & 37.5 \\
\hline 403 & 1.5 & 187 & 51.0 & 242 & 26.5 \\
\hline 167 & 58.5 & 247 & 24.0 & 272 & 16.0 \\
\hline 154 & 60.0 & 259 & 21.0 & 262 & 18.5 \\
\hline 122 & 68.0 & 297 & 13.0 & 316 & 9.0 \\
\hline 151 & 61.5 & 233 & 30.0 & 349 & 6.0 \\
\hline 403 & 1.5 & 311 & 11.0 & - & - \\
\hline 119 & 69.0 & 374 & 4.0 & - & - \\
\hline 150 & 63.0 & 206 & 43.5 & - & - \\
\hline 192 & 48.5 & 314 & 10.0 & - & - \\
\hline 111 & 72.0 & 268 & 17.0 & - & - \\
\hline 135 & 66.0 & 212 & 41.0 & - & - \\
\hline 169 & 57.0 & 339 & 7.0 & - & - \\
\hline 213 & 40.0 & 228 & 31.5 & - & - \\
\hline 192 & 48.5 & 206 & 43.5 & - & - \\
\hline 112 & 71.0 & 242 & 26.5 & - & - \\
\hline
\end{tabular}

Table 2: Mann-Whitney U-test of significance 1986 and 2010 roads network
Shimble index of 11,276 . Thus, the difference in the patterns of nodal accessibility is real and hence likely to have significant influence on the general pattern of interaction in the study area.

Spatial interaction between nodes is a function of many factors. For example, population, nodal functions, route quality, etc. are among the important measures of potential or real interaction. In the absence of data on nodal functions and route quality, nodal population is used as a surrogate for potential interaction to correlate nodal accessibility with spatial interaction in the region. A Spearman's rank correlation coefficient, $r=0.174$ was calculated which is indeed low. The ranked correlation coefficient has been found to be insignificant at the 0.05 level which suggests that the second hypothesis that

\begin{tabular}{|c|c|c|c|c|c|c|}
\hline \multirow[b]{2}{*}{$\begin{array}{l}\text { Nodal } \\
\text { name }\end{array}$} & \multicolumn{2}{|c|}{ Interaction potential } & \multirow[b]{2}{*}{$\begin{array}{l}\text { Nodal } \\
\text { index }\end{array}$} & \multirow[b]{2}{*}{$\begin{array}{c}\text { Accessibility } \\
\text { rank }\end{array}$} & \multirow[b]{2}{*}{$\begin{array}{c}\text { Rank } \\
\text { (d) }\end{array}$} & \multirow[b]{2}{*}{$\begin{array}{c}\text { Difference } \\
\left(\mathrm{d}^{2}\right) \\
\end{array}$} \\
\hline & Pop. 2001 & Rank & & & & \\
\hline Gubio & 10388 & 25 & 215 & 12.5 & 12.5 & 156.25 \\
\hline Bama & 39175 & 11 & 241 & 20.5 & -9.5 & 90.25 \\
\hline Auno & 17318 & 18 & 189 & 5.0 & 13.0 & 169.00 \\
\hline Biu & 48987 & 8 & 173 & 1.5 & 6.5 & 42.25 \\
\hline Damaturu & 18007 & 17 & 197 & 6.0 & 11.0 & 121.00 \\
\hline Damboa & 15572 & 20 & 173 & 1.5 & 18.5 & 342.25 \\
\hline Fika & 45151 & 9 & 250 & 26.0 & -17.0 & 289.00 \\
\hline Gashua & 54745 & 6 & 253 & 27.0 & -21.0 & 441.00 \\
\hline Geidam & 75213 & 4 & 260 & 29.0 & -25.0 & 625.00 \\
\hline Gwoza & 7446 & 36 & 207 & 10.0 & 26.0 & 676.00 \\
\hline Kukawa & 12328 & 23 & 320 & 41.0 & -18.0 & 324.00 \\
\hline Maiduguri & 202033 & 1 & 18 & 4.0 & -3.0 & 9.00 \\
\hline Mongonu & 15544 & 21 & 247 & 25.0 & -4.0 & 16.00 \\
\hline Ngala & 10742 & 24 & 259 & 28.0 & -4.0 & 16.00 \\
\hline Nguru & 79049 & 3 & 297 & 36.0 & -33.0 & 1089.00 \\
\hline Potiskum & 71015 & 5 & 233 & 19.0 & -14.0 & 196.00 \\
\hline Damasak & 8321 & 29 & 221 & 15.5 & 13.5 & 182.25 \\
\hline Bali & 8659 & 27 & 311 & 38.0 & -11.0 & 121.00 \\
\hline Belel & 8043 & 34 & 262 & 30.5 & 3.5 & 12.25 \\
\hline Gembu & 6226 & 41 & 374 & 45.0 & -4.0 & 16.00 \\
\hline Gombi & 8268 & 30 & 206 & 8.5 & 21.5 & 462.25 \\
\hline Ibi & 25834 & 14 & 314 & 39.0 & -25.0 & 625.00 \\
\hline Jada & 21156 & 16 & 268 & 32.0 & -16.0 & 256.00 \\
\hline Jalingo & 27714 & 13 & 212 & 11.0 & 2.0 & 4.00 \\
\hline Sabongida & 8141 & 32 & 339 & 42.0 & 10.0 & 100.00 \\
\hline Mayo-Belwa & a 14842 & 22 & 228 & 17.5 & 4.5 & 20.25 \\
\hline Michika & 17015 & 19 & 206 & 8.5 & 10.5 & 110.25 \\
\hline Mubi & 42742 & 10 & 242 & 22.5 & -12.5 & 156.25 \\
\hline Takum & 22602 & 15 & 356 & 44.0 & -29.0 & 841.00 \\
\hline Wukari & 51938 & 7 & 277 & 34.0 & -27.0 & 729.00 \\
\hline Yola & 81653 & 2 & 243 & 24.0 & -22.0 & 484.00 \\
\hline Numan & 29845 & 12 & 183 & 3.0 & 9.0 & 81.00 \\
\hline Gariye & 10135 & 26 & 308 & 37.0 & -11.0 & 121.00 \\
\hline Lau & 6742 & 38 & 228 & 17.5 & 20.5 & 420.25 \\
\hline Dakka & 6419 & 40 & 290 & 35.0 & 5.0 & 25.00 \\
\hline Buni & 6182 & 42 & 198 & 7.0 & 35.0 & 1225.00 \\
\hline Dapchi & 7095 & 37 & 221 & 15.5 & 21.5 & 462.25 \\
\hline Dikwa & 8576 & 28 & 220 & 14.0 & 14.0 & 196.00 \\
\hline Gajigana & 6673 & 39 & 215 & 12.5 & 26.5 & 702.25 \\
\hline Mutumbiyu & 79032 & 35 & 242 & 22.5 & 12.5 & 156.25 \\
\hline Garba Chede & 6029 & 45 & 272 & 33.0 & 12.0 & 144.00 \\
\hline Arege & 6178 & 43 & 262 & 30.5 & 12.5 & 165.25 \\
\hline Baga & 8096 & 33 & 316 & 40.0 & -7.0 & 49.00 \\
\hline Karamti & 6057 & 44 & 349 & 43.0 & 1.0 & 1.00 \\
\hline Song & 8149 & 31 & 241 & 20.5 & 10.5 & 110.25 \\
\hline
\end{tabular}

Table 3: Spearman's rank correlation of nodal accessibility and interaction 
there is a functional relationship between network structures and regional characteristics is rejected. From the analysis the population factor accounted for only about $3.0 \%$ of the relationship as revealed by the coefficient of determination $\mathrm{r}^{2}=0.0302$. This implies that population alone cannot adequately account for spatial interaction in any region. Other variables like regional production of goods and services, political status, centrality in service delivery, etc. are also important (Table 3).

\section{CONCLUSION}

The spatial and temporal differences in network patterns in the Northeastern part of Nigeria are real. Significant improvements in the nodal connectivity and accessibility have been achieved during the period (1955-2010). However, there is still remarkable difference between the actual and the potential connectivity and accessibility (i.e., the achieved and the maximum possible interaction) in this part of the country even though Nwafor (1982a, b) was of the view that remarkable developments in the whole country was attained in the 1980 's. The improvements in the 2010 structure could be attributed to other factors than just population size. The acquisition of new political status by some of the nodes (e.g. as local government headquarters, development area headquarters, service towns, etc.) may have contributed significantly. Moreover, the oil boom days of the early 1970 's in Nigeria also witnessed increased public sector investment in both social and economic infrastructure (including road transport) across the country. However, these may be mere speculations because a study of network using the graph method is not efficient enough to arrive at these conclusions. Although, the introduction of some ad-hoc development programs such as the Directorate of Food, Roads and Rural Infrastructure in 1983, the River Basin Development Authority's 1976, etc. are other factors that had contributed to the network change in the country as witnessed in rural Georgia based on an assessment of the impact of rehabilitation projects (Lokshin and Yemtsov, 2003), there is still the need to incorporate a multivariate approach to network and spatial interaction studies of this kind in future studies if a more realistic improvements is to be aimed.

\section{REFERENCES}

Akinola, R.A. and I.A. Adalemo, 1978. Transportation. In: Atlas of the Federal Republic of Nigeria, Adebekun, O., G.E.K. Ofomata, M.O. Filani, A.L. Mabogunje and J.S. Oguntoyinbo et al. (Eds.), 1st Edn., Federal Republic of Nigeria, Nigeria.
Akintola, F.O., 1982. Nigeria-Relief and Drainage. In: Nigeria in Maps, Barbour, K.M., J.S. Oguntoyinbo, J.O.C. Onyemelukwe and J.C. Nwafor (Eds.), Hodder and Stoughton Ltd., London, pp: 8-9.

Bashir, A., 1982. The role of transportation in the agricultural development of gongola state. B.Sc. Thesis, University of Maiduguri, Nigeria.

Gauthier, H.L., 1973. Geography, Transportation and Regional Development. In: Transport and Development, Hoyle, B.S. (Eds.). Macmillan, UK.

Hay, A., 1973. Transport for the Space Economy: A Geographical Study. Macmillan, US.

Hoyle, B.S., 1973. Transport and Economic Growth in Developing Countries. In: Transport and Development, Hoyle, B.S. (Eds.). Macmillan, UK.

Kansky, K.J., 1963. Structure of transportation networks: Relationship between network geometry and regional characteristics. University of chicago department of geography, Research Paper No. 84.

Lokshin, M. and R. Yemtsov, 2003. Evaluating the impact of infrastructure rehabilitation projects on household welfare in rural georgia. World bank policy research working paper 3155, October, 2003.

Loure, J.C. and S. Moryadas, 1975. The Geography of Movement. HM Company Boston, USA.

Nwafor, J.C., 1982a. Nigeria-Communications. In: Nigeria in Maps, Barbour, K.M., J.S. Oguntoyinbo, J.O.S., Onyemelukwe and J.C. Nwafor (Eds.), Hodder and Stoughton Ltd., London, pp: 124-125.

Nwafor, J.C., 1982b. Transportation 1-Rail. In: Nigeria in Maps, Barbour, K.M., J.S. Oguntoyinbo, J.O.C. Onyemelukwe and J.C. Nwafor (Eds.), Hodder and Stoughton Ltd., London, pp: 126-127.

Taaffe, E.J., H.L. Gauthier and M.E. O'Kelly, 1996. Geography of Transportation. 2nd Edn., Prentice Hall, India.

Taaffe, E.J., R.L. Morrill and P.R. Gould, 1963. Transport expansion in underdeveloped countries. Geog. Rev., 53: 503-529.

UNDP, 2001. Human development report 2001: Making technologies work for human development. Oxford University Press.

Weiping, H. and W. Chi, 2010. Urban road network accessibility evaluation method based on gis spatial analysis techniques. School of Geography, South China Normal University, Shipai, Guangzhou, P.R. China. http://www.isprs.org/proceedings/xxxviii/ part2/papers/130_paper.pdf.

Werner, C., 1968. The law of refraction in transportation geography: Its multivariate extension. The Canadian Geographer/Le Geographe canadien, 12: 28-40. 